\title{
S6-RNase Is a Marker for Self-compatibility in Loquat (Eriobotrya japonica Lindl.)
}

\author{
Reut Niska \\ Migal, Galilee Technology Center, P.O. Box 831, Kiryat Shmona 11016, \\ Israel
}

\begin{abstract}
Martin Goldway
Migal, Galilee Technology Center, P.O. Box 831, Kiryat Shmona 11016, Israel; and the Department of Biotechnology, Faculty of Life Sciences, Tel-Hai Academic College, Upper Galilee, 12210, Israel
\end{abstract}

\section{Doron Schneider ${ }^{1}$ \\ Migal, Galilee Technology Center, P.O. Box 831, Kiryat Shmona 11016, Israel}

Additional index words. gametophytic self-incompatibility, self- and cross-fertilization, crosspollination, progeny analysis

\begin{abstract}
Loquat (Eriobotrya japonica Lindl.), a member of the Rosaceae, carries the RNase-dependent gametophytic self-incompatibility fertilization system. Analysis of $S$-RNase-allele content in the commercial loquat cultivars Avri, Yehuda, and Akko 1 revealed that each of them contains one different $S$-RNase allele-S2, S3, and $S 4$, respectively, and one that they all share, $S 6$. Although all four $S$-alleles were isolated in this work, only $S 6$ was found to be novel. Amino acid similarity between the partial sequence of $S 6$-RNase and other known loquat RNases (S1 to $S 4$ ) ranged between $62 \%$ and $65 \%$ with highest similarity $(83 \%)$ to the $S 110$-allele of European pear (Pyrus communis). Determination of $S$-RNase-allele content in progeny of 'Avri', 'Yehuda', and 'Akko 1', obtained in an open-pollinated, mixed-cultivar orchard, revealed that all of the progeny derived from self-fertilization contained the $S 6$ haplotype, indicating that a mutation in the $S 6$ locus is responsible for the self-fertilization. However, sequencing of most of the S6-RNase gene (from $\mathrm{C} 1$ to $\mathrm{C5}$ ) did not reveal any mutation and the alignment of the deduced amino acid sequence showed that it has the expected $S$-RNase primary and tertiary structural organization. Nonetheless, because it is apparent that the S6-RNase allele is linked to the self-compatibility trait, it could serve as a marker for early selection of self-compatible loquat cultivars.
\end{abstract}

Loquat (Eriobotrya japonica Lindl.) is a subtropical evergreen fruit tree of the family Rosaceae, subfamily Maloideae (Lin et al., 1999), which carries the RNase-dependent gametophytic self-incompatibility fertilization system. This system is controlled by a single multiallelic locus ( $S$-locus) that contains at least two haplotype-specific genes: the $S$-RNase gene, which is expressed in the pistil, and a pollen $S$ gene, expressed in the pollen tube (Kao and Tsukamoto, 2004; McCubbin and Kao, 2000). However, some loquat cultivars such as 'Akko 1', 'Mogi', 'Pale Yellow', 'Advance', and 'Tanaka' are selffertile or partially self-fertile (Cuevas et al., 2003; Morton, 1987; Tous and Ferguson, 1996).

In the Maloideae subfamily, selfcompatibility has been shown to occur as

Received for publication 6 Mar. 2010. Accepted for publication 14 June 2010.

We thank Gershon Mainheart, Ella Ofek, Aharon Moshe, and Nili Shemi for their cooperation and valuable assistance in collecting the data.

${ }^{1}$ To whom reprint requests should be addressed; e-mail Doronsc@migal.org.il. a result of mutation in the $S$-RNase gene: the self-compatible Japanese pear (Pyrus pyrifolia) cv. Osa-Nijisseiki carries a deletion in the $S 4$ locus that includes the $S$-RNase gene (Okada et al., 2008) and the European pears (Pyrus communis) 'Abugo' and 'Ceremeno' are selfcompatible as a result of the absence of $S 21^{\circ}$ RNase protein in their styles (Sanzol, 2009).

From an agricultural point of view, selfcompatibility provides an advantage in that an orchard can contain a single cultivar (solid block) as opposed to self-incompatible cultivars that depend on cross-pollination of a compatible cultivar with synchronous flowering. Nevertheless, in loquats, cross-pollination is generally considered to be beneficial in terms of productivity (Crane and Caldeira, 2006; McGregor, 1976; Morton, 1987; Thapa, 2006). For example, artificial cross-pollination of cv. Algerie resulted in more fruits of larger size with more seeds than artificial self-pollination (Cuevas et al., 2003), and cross-pollination of cv. Jiefangzhong increased its fruit weight (Xu et al., 2007).

In Israel, 'Akko 1' and 'Yehuda' are the main commercial cultivars, whereas 'Avri' is a new cultivar that is widespread in new plantations. The three cultivars were bred from local chance seedlings. They are considered self-fertile and are usually planted in solid blocks. In this study, the $S$-genotype of the loquat cultivars Avri, Yehuda, and Akko 1 and their progeny was determined, indicating that the S6-RNase allele can be used as a marker for the identification and selection of self-compatible cultivars.

\section{Materials and Methods}

The orchard. The experiment was conducted in a 0.3 -ha loquat orchard planted in 2002 at 440 trees/ha spaced at $6 \times 4 \mathrm{~m}$. The nearest loquat orchard is $5 \mathrm{~km}$ away. The orchard is located north of the Sea of Galilee (long. $36^{\circ} \mathrm{N}$, lat. $29.9^{\circ} \mathrm{E}$, alt. $0 \mathrm{~m}$ ) in a semiarid region with high temperatures $\left(\approx 42{ }^{\circ} \mathrm{C}\right.$ maximum). Winter precipitation (November to April) is $\approx 400 \mathrm{~mm}$. The orchard contains six rows of 'Yehuda' as a single cultivar, apart from the fourth row in which 'Avri' and 'Akko 1 ' were planted between 'Yehuda' along the row in alternating fashion (i.e., 'Yehuda', 'Avri', 'Yehuda', 'Akko 1', 'Yehuda', 'Avri', 'Yehuda', 'Akko 1', and so on). The three cultivars flowered simultaneously during Oct. 2008. Fruit ripened early, between 15 Feb. and 5 Apr. 2009.

Plant material. For DNA analysis, young leaves were collected from the parental cultivars Avri, Yehuda, and Akko 1 and from 4-month-old seedlings of their progeny. Seedlings were obtained from seeds that were isolated at harvest, sown in boxes containing peat rooting medium, and left for germination in a nursery. The progeny $S$-RNase analysis was performed on one or two seedlings obtained from a single fruit. The leaves were stored at $-70{ }^{\circ} \mathrm{C}$ until use.

DNA extraction. DNA was extracted from the leaves according to Doyle and Doyle (1987) with modifications. Briefly, $700 \mu \mathrm{L}$ of extraction buffer $(2 \% \mathrm{w} / \mathrm{v}$ hexadecyltrimethylammonium bromide, $100 \mathrm{~mm}$ Tris- $\mathrm{HCl} \mathrm{pH} 8$, $20 \mathrm{~mm}$ ethylenediamine tetraacetic acid $\mathrm{pH} 8$, $1.4 \mathrm{M} \mathrm{NaCl}, 1 \% \mathrm{w} / \mathrm{v}$ polyvinylpyrrolidone MW 40,000, 1\% v/v $\beta$-mercaptoethanol) was added to 100 to $200 \mathrm{mg}$ of leaves, which had been frozen in liquid nitrogen and pulverized with a mortar and pestle. This mixture was incubated for $30 \mathrm{~min}$ at $65{ }^{\circ} \mathrm{C}$ with occasional mixing. After the mixture cooled to room temperature, two extractions were performed with chloroform:octanol $(24: 1, v / v)$. The DNA was pelleted with ethanol and dissolved in double-distilled water. The DNA extract was kept at $-20^{\circ} \mathrm{C}$ pending use.

Polymerase chain reaction amplification. The polymerase chain reaction (PCR) was performed in a MyCycler apparatus (BioRad, Hercules, CA). The basic program was as follows: 1 cycle of $2 \mathrm{~min}$ at $94{ }^{\circ} \mathrm{C}, 30$ cycles of $15 \mathrm{~s}$ at $94^{\circ} \mathrm{C}, 30 \mathrm{~s}$ at the specific annealing temperature (Table 1), and $2 \mathrm{~min}$ at $70^{\circ} \mathrm{C}$; the final cycle was $7 \mathrm{~min}$ at $70^{\circ} \mathrm{C}$. Each PCR tube contained $\approx 20$ ng DNA, $1 \times$ Ex Taq buffer (Takara Bio Inc., Shiga, Japan), $0.2 \mathrm{~mm}$ dNTP mixture, $20 \mathrm{pmol}$ of each primer, and 
Table 1. Conditions and primers for polymerase chain reaction of loquat $S$-RNase genes.

\begin{tabular}{|c|c|c|c|c|c|}
\hline $\begin{array}{l}R \text { Nase } \\
\text { gene }\end{array}$ & Accession no. & Forward primer $\left(5^{\prime} \rightarrow 3^{\prime}\right)$ & Reverse primer $\left(5^{\prime} \rightarrow 3^{\prime}\right)$ & $\begin{array}{l}\text { Fragment } \\
\text { length (bp) }\end{array}$ & $\begin{array}{l}\text { Annealing } \\
\text { temp. }\left({ }^{\circ} \mathrm{C}\right)\end{array}$ \\
\hline$S 2$ & GU384665 & $\begin{array}{l}\text { AATAAAACCATGAATTCCCTGGC } \\
(133-155)\end{array}$ & $\begin{array}{l}\text { CTGCAAAGASTRAYCTCAACC } \\
\text { [S2-(627-647), S4- }(654-674) \\
\text { and } S 6-(604-624)]\end{array}$ & 514 & 52 \\
\hline$S 3$ & GU384666 & $\begin{array}{l}\text { GGTAATTGCTAGATAGACTAA } \\
(274-294)^{\mathrm{y}}\end{array}$ & As for $S 2$ & $539^{x}$ & 56 \\
\hline$S 4$ & GU384667 & $\begin{array}{l}\text { GCATACCAGAGAGAAAAATTA } \\
(319-339)^{y}\end{array}$ & As for $S 2$ & 355 & 56 \\
\hline
\end{tabular}

${ }^{2}$ Universal primers of Pyrus pyrifolia S-RNases (Ishimizu et al., 1998).

${ }^{\mathrm{y}} \mathrm{Part}$ or all of the primer is located within the intron.

${ }^{\mathrm{x}}$ Fragment length based on deduced gene sequence.

1.25 U of Ex Taq (Takara Bio Inc.) in $25 \mu \mathrm{L}$ of reaction mixture. The universal primers were those used initially by Ishimizu et al. (1998) for the amplification of $P$. pyrifolia $S$-RNases. For amplification of each specific $S$-RNase, a unique forward primer was generated for each of the alleles and a degenerated reverse primer was generated for $S 2, S 3$, S4, and S6-RNase (Table 1).

Cloning and DNA sequencing of polymerase chain reaction products. PCR products were cloned into pGEMT (Promega, Madison, WI) and sequenced in both directions. At least two different clones were sequenced for each $S$-RNase. The sequencing was performed with an ABI 3730 XL automated DNA sequencer (PE Bio System, Foster, CA) using dye terminator cycle sequencing with fluorescently labeled dye terminators.

DNA and putative protein sequence analyses. Analyses of the DNA sequence data and of the predicted protein sequences were performed with BLAST of NCBI, Clustal W and the phylogenetic tree at EMBL BoxShade server (http://www.ebi.ac.uk/clustalw/index. $\mathrm{html}$ ), and the DNAstar Lasergene 6 "SeqManII" software (Madison, WI).

S-RNase structure modeling and alignment. Models were created with the Swiss Model Workspace (Arnold et al., 2006) and aligned with the PyMOL Molecular Graphics System (2002) (DeLano Scientific, San Carlos, CA).

\section{Results}

The S-genotype of cvs. Avri, Yehuda, and Akko 1. Each of the S-RNase alleles from 'Avri', 'Yehuda', and 'Akko 1' was cloned and sequenced independently. Alignment of the clones to each other and to GenBank revealed that 'Avri' is S2-S6 (Accession Nos. GU384665 and GQ202269, respectively), 'Yehuda' is $S 3$ S6 (Accession Nos. GU384666 and GQ202269, respectively), and 'Akko 1' is $S 4-S 6$ (Accession Nos. GU384667 and GQ202269, respectively). Thus, they all share the $S 6-R$ Nase allele. $S 2, S 3$, and $S 4-R N a s e$ have also been recently cloned by Carrera et al. (2009) (Accession Nos. EU442286, EU442287, and EU442289, respectively), whereas $S 6$ is a novel allele. Nevertheless, the sequences of $S 2, S 3$, and S4-RNases were deposited in GenBank, because they were 24 to 94 bases longer than those of Carrera et al. (2009).
The loquat S6-RNase. Because S6-RNase is carried by 'Avri', 'Yehuda', and 'Akko 1', three cultivars that are assumed to be selfcompatible, we hypothesized that selffertilization might be the result of mutation in the S6-RNase gene.

The segment cloned from the S6-RNase allele contained $\approx 80 \%$ of the gene's open reading frame. $S$-RNase genes carry an intron within the hypervariable (HV) region. The intron of loquat S6-RNase was localized to this native position and was 124 bases long. The deduced amino acid sequence of the two exons exhibited highest similarity (83\%) with European pear (Pyrus communis) S110-RNase (also designated $\mathrm{S10}$ or $\mathrm{Sg}$, Accession Nos. $\mathrm{AB} 258360$ and EF418041, respectively; Goldway et al., 2009). Amino acid identity between the S6-RNase and loquat S1-S4 RNases ranged between $62 \%$ and $65 \%$ (Fig. 1).
The putative S6-RNase amino acid sequence possessed the primary structural features of all known $S$-RNases. S6-RNase was cloned from the border of $\mathrm{C} 1$ to the border of C5 conserved regions and contained the three other conserved regions, $\mathrm{C} 2, \mathrm{C} 3$, and $\mathrm{RC} 4$. It also included the $\mathrm{HV}$ region and the five conserved cysteine and two conserved histidine residues (Fig. 1), which have been shown to be essential for RNase activity in the Solanaceae (Royo et al., 1994).

The computerized protein structures of S2- and S6-RNases from loquat were generated and compared revealing a similar structure, except for the HV region (Fig. 2).

Polymerase chain reaction analysis of $\mathrm{S}-R$ Nase alleles in the progeny. To characterize the fertilization and pollination types of 'Avri', 'Yehuda', and 'Akko 1' in a mixed-cultivar commercial orchard, $S$-RNase allele distribution
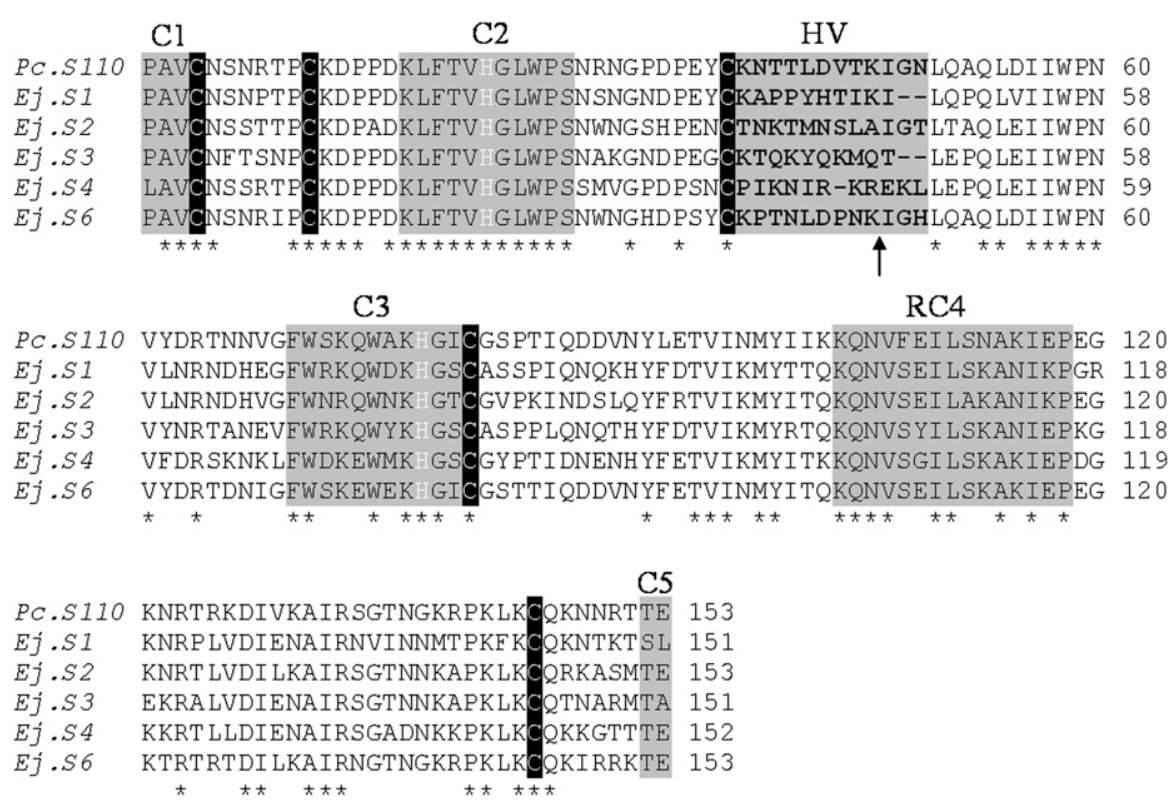

Fig. 1. Amino acid alignment of loquat $S$-RNases. The alignment was generated by Clustal W 1.8 . Similarities are shown by asterisks and gaps are marked by dashes. The conserved regions (C1 to C5) are shaded. The hypervariable region (HV) is shaded with characters in bold type. The conserved cysteines (white characters on black background) and histidines (white characters on gray background) are indicated. $S 6$-RNase intron position is marked with an arrow. The aligned $S$-RNase sequences are from S1, S2, S3, S4, and S6 alleles of loquat (Eriobotrya japonica, Ej) (Accession Nos. ACC66149, ADC92282, ADC92283, ADC92284, and ACS94938, respectively) and from the $S 110$-allele of European pear (Pyrus communis, Pc) (also designated S10 or Sg, Accession Nos. ABR08577 and BAF35959, respectively). 
was determined in their open-pollinated progeny. Fruits were collected from adjacent 'Avri', 'Yehuda', and 'Akko 1' trees and PCR analysis for $S$-RNase alleles was performed on leaves of seedlings raised from the seeds of the collected fruits. For the analysis, specific primer pairs were generated for loquat $S 2, S 3, S 4$, and $S 6$ RNase (Table 1; Fig. 3).

Because we assumed that self-compatibility is the result of a malfunction in the $S 6$ locus, we expected that the progeny derived from self-fertilization would all carry the S6-RNase, half of them in the homozygous state and the other half in the heterozygous state, with the second allele being the other parental S-RNase. The analysis revealed that all of the self-fertile progeny contained the $S 6$ haplotype (Table 2). Some of them were obtained by self-pollination and some by cross-pollination, because all of

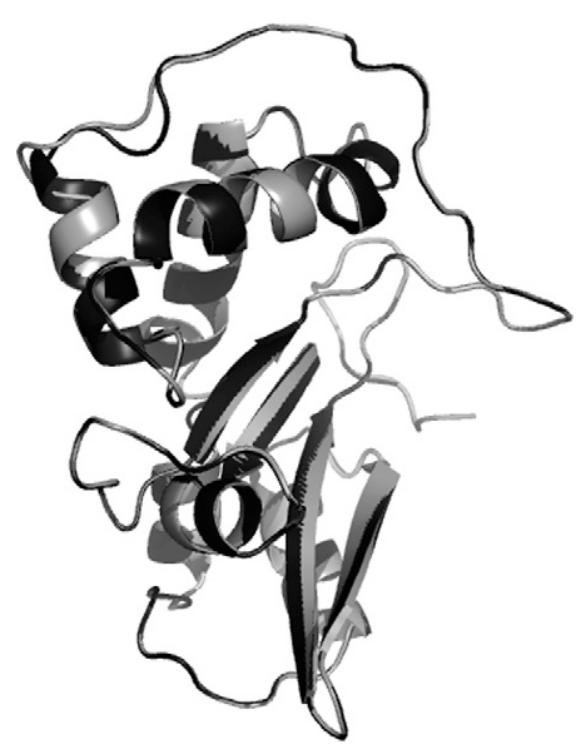

Fig. 2. Stereo ribbon diagram of $S 2$ - and $S 6$-RNases from loquat (black and gray, respectively).

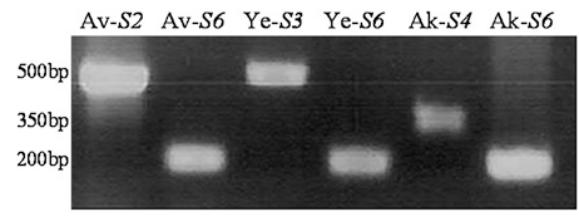

Fig. 3. Identification of $S$-RNase-allele content in loquat cvs. Avri (Av), Yehuda (Ye), and Akko 1 (Ak) by polymerase chain reaction with specific primers (primers are described in "Materials and Methods"; Table 1). the pollen donors in the orchard contained the

S6 locus. The distribution between the S6 homozygous and heterozygous (with the other parental $S$-allele) states was, respectively, $71 \%$ and $29 \%$ in 'Avri', 67\% and 33\% in 'Yehuda', and $52 \%$ and $48 \%$ in 'Akko 1 ' (Table 2).

Cross-pollination levels were determined by the non-parental $S$-RNase allele (Tables 2 and 3). For example, the seven 'Avri' progeny that were the outcome of non-S6 pollen fertilization (S6-S3 and $S 2-S 3$ ) were identified by the $S 3$-allele of 'Yehuda' (Table 2). If the same number of 'Avri' progeny was obtained by self-fertilization with 'Yehuda' S6pollen grain, then the total cross-pollination level of 'Avri' open-pollinated progeny, obtained in the mixed-cultivar orchard, was $46 \%$ (14 of 31 progeny). By using this same method, the total cross-pollination rates of 'Yehuda' and 'Akko 1' were found to be 10\% and $32 \%$, respectively (Table 3 ).

\section{Discussion}

The $S$-RNase-allele content of three commercial loquat cultivars that are considered to be self-compatible was determined. It was found that 'Avri', 'Yehuda', and 'Akko 1' contain one unique $S$-RNase: $S 2, S 3$, and $S 4$, respectively, and that the other allele, $S 6$, is present in all of them. Although all four $S$-alleles were isolated in this work, only $S 6$ was novel. The $S 6$-RNase exhibited the highest amino acid identity to the European pear (P. communis) $S 110$ allele (83\%), whereas it showed only $62 \%$ to $65 \%$ identity to the loquat $S$-RNases. Thus, similar to many other cases (Ishimizu et al., 1998; Zisovich et al., 2004), including another study on loquat $S$ RNases (Carrera et al., 2009), the S6-RNase exhibits a transspecific pattern, suggesting that some of the polymorphism at the $S$-locus existed before divergence of the Maloideae species.

Self-fertilization in an open-pollinated, mixed-cultivar orchard containing 'Avri', 'Yehuda', and 'Akko 1' was determined by PCR analysis of progeny $S$-RNase alleles (concluded by the presence of the parental $S$-RNase alleles). Because all of the progeny derived from self-fertilization carried the S6-RNase allele, it was concluded that the $S 6$ locus is responsible for this self-fertilization: $77 \%$ to $95 \%$ of the three cultivars' progeny were the outcome of self-fertilization with the S6 pollen grain, indicating dysfunction of a main component in the fertilization system.

No insertions or deletions were detected in the S6-RNase sequence from the border of $\mathrm{C} 1$ to the border of $\mathrm{C} 5$ (covering $\approx 80 \%$ of the

Table 2. S-allele distribution in 'Avri', 'Yehuda', and 'Akko 1' progeny obtained from open pollination in a mixed-cultivar orchard in 2008-2009.

\begin{tabular}{lcccccccc}
\hline $\begin{array}{l}\text { Cultivar } \\
\text { progeny }\end{array}$ & $\begin{array}{c}\text { Progeny with parental } S \text { alleles } \\
\text { (self-fertilization) }\end{array}$ & \multicolumn{9}{c}{$\begin{array}{c}\text { Progeny with a non-parental } \\
\text { allele (cross-fertilization) }\end{array}$} & $\begin{array}{c}\text { No. } \\
\text { progeny }\end{array}$ \\
\hline Avri $(S 6-S 2)$ & $S 6-S 6$ & $S 2-S 2$ & $S 6-S 2$ & $S 6-S 3$ & $S 6-S 4$ & $S 2-S 3$ & $S 2-S 4$ & \\
& 17 & 0 & 7 & 3 & 0 & 4 & 0 & 31 \\
Yehuda (S6-S3) & $S 6-S 6$ & $S 3-S 3$ & $S 6-S 3$ & $S 6-S 2$ & $S 6-S 4$ & $S 3-S 2$ & $S 3-S 4$ & \\
& 24 & 0 & 12 & 0 & 2 & 0 & 0 & 38 \\
Akko 1 (S6-S4) & $S 6-S 6$ & $S 4-S 4$ & $S 6-S 4$ & $S 6-S 2$ & $S 6-S 3$ & $S 4-S 2$ & $S 4-S 3$ & \\
& 16 & 0 & 15 & 0 & 2 & 0 & 4 & 37 \\
\hline
\end{tabular}

gene). Alignment of the deduced amino acid sequence and a computer-generated protein structure showed that it has the expected $S$-RNase primary, secondary, and tertiary structural organization (Ishimizu et al., 1998; Matsuura et al., 2001). Nevertheless, because the $5^{\prime}$ and $3^{\prime}$ ends of S6-RNase were not sequenced and its expression and function were not analyzed, this RNase cannot be conclusively determined as the reason for the breakdown of the fertilization system. Another possibility that would enable self-fertilization is dysfunction of the pollen $S$-gene. The $S F B$ protein, a pollen $S$-haplotype-specific F-box protein gene, has been shown to confer selfcompatibility in sweet cherry (Prunus avium), Japanese apricot (Prunus mume), peach (Prunus persica), and apricot (Prunus armeniaca) (Sonneveld et al., 2005; Tao et al., 2007; Ushijima et al., 2004; Vilanova et al., 2006). However, all of these fruits belong to the Amygdaloideae, whereas loquats are from the subfamily Maloideae. According to Sassa et al. (2007), there are two (in apple) or three (in pear) F-box brother (SFBB) genes, which are located in the $S$-locus and expressed in the pollen, and they are candidates for this role in the Maloideae subfamily. However, to date, there has been no report of a mutation in an SFBB conferring self-fertilization at all.

It was expected that among the selffertilized progeny, $50 \%$ would be homozygous for $S 6$, and the other $50 \%$ would be heterozygous for $S 6$ and the $S$-RNase allele of the maternal $S$-haplotype as has been found for progeny of the partly self-compatible Japanese pear (Pyrus serotina) cv. Osa Nijisseiki (S2S4 $\left.{ }^{s m}\right)$ (Hiratsuka et al., 1995) and the partly self-compatible Japanese apricot (Prunus mume) cv. Hachiro (S8Sf) (Tao et al., 2002). The distribution among 'Akko 1' progeny was as expected; however, in 'Avri' and 'Yehuda', there was a bias of $71 \%$ and $67 \%$, respectively, for $S 6$-homozygous progeny. The reason for this imbalanced preference is not clear to us; it could be coincidental or the result of biological reasons such as an advantage for fertilization of $S 6$ haplotype ovules by $S 6$ haplotype pollen or a higher probability of seedling formation by seeds that are homozygous for $S 6$. Regardless, the results clearly indicate that the $S 6$-RNase is linked to the self-compatibility trait in loquats and that it can be applied as a marker for the identification and selection of self-compatible cultivars.

Cross-pollination level of 'Avri', 'Yehuda', and 'Akko 1' was $46 \%, 10 \%$, and $32 \%$, respectively. The lower rate of cross-pollination in 'Yehuda' could be because it was the main cultivar in the orchard and/or as a result of its flower properties, which were not examined in this study. Accordingly, all 'Avri' and 'Akko 1' cross-fertile progeny were the outcome of fertilization with 'Yehuda' $S 3$ pollen. However, the high rate of cross-pollination in 'Avri' and 'Akko 1', obtained in a mixed-cultivar orchard, implies honeybees' and other insects' contribution to loquat fruit set, as reported by others (Crane and Caldeira, 2006; Cuevas et al., 2003; McGregor, 1976; Morton, 1987; Thapa, 2006). According to Cuevas et al. 
Table 3. Cross-pollination levels in open-pollinated 'Avri', 'Yehuda', and 'Akko 1' progeny obtained in a mixed-cultivar orchard in 2008-2009.

\begin{tabular}{|c|c|c|c|}
\hline $\begin{array}{l}\text { Cultivar } \\
\text { progeny }\end{array}$ & $\begin{array}{l}\text { Cross-pollination } \\
\text { with non-S6 } \\
\text { pollen grains }(\%)^{z}\end{array}$ & $\begin{array}{c}\text { Assumed cross-pollination } \\
\text { with } S 6 \\
\text { pollen grains }(\%)\end{array}$ & $\begin{array}{c}\text { Total cross-pollination } \\
\text { with } S 6 \text { and non-S6 } \\
\text { pollen grains }(\%)\end{array}$ \\
\hline Avri $(S 6-S 2)$ & $23 \%(7 / 31)$ & $23 \%(7 / 31)$ & $46 \%(14 / 31)$ \\
\hline Yehuda $(S 6-S 3)$ & $5 \%(2 / 38)$ & $5 \%(2 / 38)$ & $10 \%(4 / 38)$ \\
\hline Akko 1 (S6-S4) & $16 \%(6 / 37)$ & $16 \%(6 / 37)$ & $32 \%(12 / 37)$ \\
\hline
\end{tabular}

${ }^{\mathrm{z}}$ According to cross-fertilization results presented in Table 2 .

(2003) and Xu et al. (2007), cross-pollination in loquat improves fruit set, seed set, and fruit size. Our results show for the first time that cross-pollination is significant in a mixedcultivar loquat orchard. Therefore, despite the existence of self-compatibility in many loquat cultivars, this strategy could be applied to improve the productivity of loquat orchards.

\section{Literature Cited}

Arnold, K., L. Bordoli, J. Kopp, and T. Schwede 2006. The SWISS-MODEL workspace: A web-based environment for protein structure homology modeling. Bioinformatics 22:195201.

Carrera, L., J. Sanzol, M. Herrero, and J.I. Hormaza. 2009. Genomic characterization of selfincompatibility ribonucleases (S-RNases) in loquat (Eriobotrya japonica Lindl.) (Rosaceae, Pyrinae). Mol. Breed. 23:539-551.

Crane, J.H. and L.M. Caldeira. 2006. Loquat growing in the Florida home landscape. Homestead: HS5; UF/IFAS. <http://edis.ifas.ufl.edu/ pdffiles/MG/MG05000.pdf>.

Cuevas, J., J.J. Hueso, and M. Puertas. 2003. Pollination requirements of loquat (Eriobotrya japonica Lind1.) cv. 'Algerie'. Fruits 58:1-9.

Doyle, J.J. and J.L. Doyle. 1987. A rapid DNA isolation procedure for small quantities of fresh leaf tissue. Phytochem. Bull. 19:11-15.

Goldway, M., T. Takasaki-Yasuda, J. Sanzol, M. Mota, A. Zisovich, R.A. Stern, and S. Sansavini. 2009. Renumbering the S-RNase alleles of European pears (Pyrus communis L.) and cloning the S109 RNase allele. Sci. Hort. 119:417422.

Hiratsuka, S., Y. Okada, Y. Kawai, F. Tamura, and K. Tanabe. 1995. Expression and inheritance of S-protein in self-compatible and incompatible
Japanese pears. J. Jpn. Soc. Hort. Sci. 64:479484.

Ishimizu, T., T. Shinkawa, F. Sakiyama, and S. Norioka. 1998. Primary structural features of rosaceous $S$-RNases associated with gametophytic self-incompatibility. Plant Mol. Biol. 37: 931-941.

Kao, T.H. and T. Tsukamoto. 2004. The molecular and genetic bases of $S$-RNase-based selfincompatibility. Plant Cell 16:S72-S83.

Lin, S., R.H. Sharpe, and J. Janick. 1999. Loquat: Botany and horticulture. Hort. Rev. (Amer. Soc. Hort. Sci.) 23:233-276.

Matsuura, T., H. Sakai, M. Unno, K. Ida, M. Sato, F. Sakiyama, and S. Norioka. 2001. Crystal structure at $1.5-\AA$ resolution of Pyrus pyrifolia pistil ribonuclease for gametophytic self-incompatibility. J. Biol. Chem. 276:45261-45269.

McCubbin, A.G. and T.H. Kao. 2000. Molecular recognition and response in pollen and pistil interactions. Annu. Rev. Cell Dev. Biol. 16: 333-364.

McGregor, S.E. 1976. Insect pollination of cultivated crop plants. Agriculture handbook 489 USDA-ARS, Washington, DC.

Morton, J. 1987. Loquat, p. 103-108. In: Morton, J.F. (ed.). Fruits of warm climates. Julia F. Morton, Miami, FL.

Okada, K., N. Tonaka, Y. Moriya, N. Norioka, Y. Sawamura, T. Matsumoto, T. Nakanishi, and T. Takasaki-Yasuda. 2008. Deletion of a $236 \mathrm{~kb}$ region around $S_{4}$-RNase in a stylar-part mutant $S_{4}^{s m}$-haplotype of Japanese pear. Plant Mol. Biol. 66:389-400.

Royo, J., C. Kunz, Y. Kowyama, M. Anderson, A.E Clarke, and E. Newbigin. 1994. Loss of histidine residue at the active-site of $S$-locus ribonuclease is associated with self-compatibility in Lycopersicon peruvianum. Proc. Natl. Acad. Sci. USA 91:6511-6514.
Sanzol, J. 2009. Pistil-function breakdown in a new $S$-allele of European pear, $S 21^{\circ}$, confers selfcompatibility. Plant Cell Rep. 28:457-467.

Sassa, H., H. Kakui, M. Miyamoto, Y. Suzuki, T. Hanada, K. Ushijima, M. Kusaba, H. Hirano, and T. Koba. 2007. S locus F-box brothers: Multiple and pollen-specific F-box genes with $S$ haplotype-specific polymorphisms in apple and Japanese pear. Genetics 175:1869-1881.

Sonneveld, T., K.R. Tobutt, S.P. Vaughan, and T.P. Robbins. 2005. Loss of pollen-S function in two self-compatible selections of Prunus avium is associated with deletion/mutation of an $S$ haplotype-specific F-box gene. Plant Cell 17: $37-51$.

Tao, R., T. Habu, A. Namba, H. Yamane, F. Fuyuhiro, K. Iwamoto, and A. Sugiura. 2002. Inheritance of Sf-RNase in Japanese apricot (Prunus mume) and its relation to self-compatibility. Theor. Appl. Genet. 105:222-228.

Tao, R., A. Watari, T. Hanada, T. Habu, H. Yaegaki, M. Yamaguchi, and H. Yamane. 2007. Self-compatible peach (Prunus persica) has mutant versions of the $S$ haplotypes found in self-incompatible Prunus species. Plant Mol. Biol. 63:109-123.

Thapa, R.B. 2006. Honeybees and other insect pollinators of cultivated plants: A review. J. Inst. Agr. Anim. Sci. 27:1-23.

Tous, J. and L. Ferguson. 1996. Mediterranean fruits, p. 416-430. In: Janick, J. (ed.). Progress in new crops. ASHS Press, Arlington, VA.

Ushijima, K., H. Yamane, A. Watari, E. Kakehi, K. Ikeda, N.R. Hauck, A.F. Iezzoni, and R. Tao. 2004. The $S$ haplotype-specific F-box protein gene, $S F B$, is defective in self-compatible haplotypes of Prunus avium and P. mume. Plant J. 39:573-586.

Vilanova, S., M.L. Badenes, L. Burgos, J. MartínezCalvo, G. Llácer, and C. Romero. 2006. Selfcompatibility of two apricot selections is associated with two pollen-part mutations of different nature. Plant Physiol. 142:629-641.

Xu, J.H., C.Z. Cheng, L.M. Zhang, Z.H. Zhang, Y.J. Xu, and S.Q. Zheng. 2007. Pollen parent effects on fruit quality of 'Jiefangzhong' 1oquat. Acta Hort. 750:361-365.

Zisovich, A.H., R.A. Stern, S. Shafir, and M. Goldway. 2004. Identification of seven $S$-alleles from the European pear (Pyrus communis) and the determination of compatibility among cultivars. J. Hort. Sci. Biotechnol. 79:101-106. 